Sarah Knight ${ }^{1}$, Aldert Vrij, Julie Cherryman, and Karl Nunkoosing

\title{
Attitudes Towards Animal Use and Belief in Animal Mind
}

\begin{abstract}
Animals are used by humans in many ways, yet science has paid little attention to the study of human-animal relationships (Melson 2002). In the present study participants $(n=96)$ completed a questionnaire on attitudes towards animal use and individual differences were examined to determine which characteristics might underlie these attitudes ('belief in animal mind', age, gender, experience of animals, vegetarianism, political stance, and living area). It emerged that participants held different views for different types of animal use, and that belief in animal mind (BAM) was a powerful and consistent predictor of these attitudes, with BAM together with gender and vegetarianism predicting up to $37 \%$ of the variance in attitudes towards animal use. Thus future research should acknowledge the importance of BAM as a major underlying factor of attitudes towards animal use, and should also distinguish between different types of animal use when measuring attitudes. We proposed that the large effect of BAM might be due to increasing interest in animal mind over the past decade.
\end{abstract}

\footnotetext{
${ }^{1}$ For correspondence please contact Sarah Knight at the above address, or e-mail sarah.knight@ port.ac.uk / tel: 02392846314 / fax: 02392846300
} 


\section{Attitudes Towards Animal Use and Belief in Animal Mind}

The term 'animal use' is used to describe a wide range of different practices that involve humans using animals. For example, for entertainment (e.g. circuses, fox hunting), for personal decoration (e.g. wearing animal fur, testing cosmetics on animals), for research (e.g. drugs testing on animals). Clearly there are differences between these uses in terms of what actually happens to animals, what the outcomes are, whether there are alternatives, and so on, yet much research has examined attitudes towards how animals are used in general (e.g. Armstrong and Hutchins 1996; Matthews and Herzog 1997), rather than looking at whether people hold different attitudes towards different ways in which animals can be used. Existing research also tends to use largely unrepresentative samples such as psychology students (Kafer, Lago, Wamboldt and Harrington 1992; Herzog and Dorr 2000). The present study differs from previous studies in that (i) it compared attitudes towards different types of animal use, (ii) since 'belief in animal mind' (BAM) has been found to be a predictor of attitudes towards animal use (e.g. Hills 1995), we tried to identify participant variables that might underlie BAM, and (iii) ours was a non-student sample.

\section{Belief in animal mind (BAM)}

BAM is the term used for how we attribute to animals mental capacities such as intellect, the ability to reason, and feelings of emotion (see Hills 1995), and has been defined and measured in a variety of ways (e.g. Herzog \& Galvin, 1997; Hills, 1995), and thus is not a single, constant measure. That we try to understand ourselves and others by hypothesising about the reasons behind actions and interactions is central to social psychology (Smith and Mackie 1995). Attribution Theory describes how people make sense of each other by attributing characteristics of that person (for example their behaviour) as influenced by external (e.g. the situation) or internal (e.g. personality) attributions (Heider 1944; Kemdal and Montgomery 2001). Thus attitude formation of a person will be influenced by the attributions associated with features of that person. Eddy, Gallup, and Povinelli (1993) suggested that BAM is a natural extension of Attribution Theory, in that BAM refers to internal attributions (such as mental states, characteristics and abilities) people believe animals to have. That is, when people do not believe animals to be capable of thinking and feeling and so on, they are more inclined to support animal use (Herzog and Galvin 1997).

\section{Experience of animals}


Attitudes towards animal use are influenced by experience of animals (Wells and Hepper 1997); for example, Driscoll (1992) found that pet owners rated animal research as less acceptable than did non-pet owners. Theoretical reasons for this relationship may relate to the 'contact hypothesis' (e.g. Allport 1954), where contact with members of an outgroup (e.g. nonhuman animals) can lead to a mutual understanding and decreased prejudice towards that group. For example, inter-ethnic contact is a highly significant negative predictor of racial prejudice (Hamberger and Hewstone 1997). Knowledge of an outgroup member through direct contact can lead people to share positive experiences and learn about positive characteristics of members of that outgroup, and as such will require the prejudiced person to question and cognitively reconstruct their (often incorrect) negative perceptions of the outgroup members. Contact may also allow an emotional attachment to develop between a prejudiced person and an outgroup member, as the two become to know each other as people rather than representatives of their group. Thus experience of animals could promote positive attitudes towards animals (e.g. by becoming emotionally attached to pets) and negative attitudes towards animal use (e.g. due to an increase in animal mind). Experience of animals may also influence attitudes towards animal use issues in terms of personal relevance, since attitudes are influenced by the personal relevance of the issue in question (e.g. Petty and Cacioppo 1990; Lieberman and Chaiken 1996). So if experience of animals (such as pet keeping) leads to people perceiving animal use issues to be more relevant to them personally, then attitudes towards such issues will be influenced by whether people have more or less experience of animals. This effect could be influence attitudes either positively or negatively depending on the type of experience with animals- a rewarding relationship with a pet could lead to less support for animal use, whereas a negative encounter with an animal may mean that people are more supportive of animal use.

\section{Gender}

Males present lower levels of BAM compared to females (Herzog and Galvin 1997), and the effects of gender on attitudes towards animal use are consistent, with males being generally more supportive of animal use (e.g. Furnham and Pinder 1990; Rajecki, Rasmussen and Craft 1993; Plous 1996; Wells and Hepper 1997), with such differences extending to at least fifteen countries (Pifer, Shimizu, and Pifer 1994). Indeed, gender differences concerning attitudes towards animals, animal use, and BAM, may have a biological basis in that there might be essential differences between male and female brain types (Baron-Cohen et al., 2002; BaronCohen, 2003). Influenced by hormonal and genetic differences, it has been suggested that more males are pre-disposed to spontaneously 'systemize' (and less likely to empathize compared to 
the females) whilst more females are more likely to spontaneously 'empathize' and less likely to systemize, compared to males (Baron-Cohen, 2003). Systemizing describes the drive and ability to understand systems, rules and regularities, which involve non-agentive events (e.g. how an engine works, or profit and loss processes in business) That is, to consider the 'facts' as inputs to a 'relationship', and based on these facts predict the outcome of the relationship. In contrast, empathizing involves two major elements: (i) the ability to attribute mental states to oneself and to others, and (ii) the ability to respond in an emotionally appropriate way to that others mental state (Baron-Cohen et al., 2002). In a sense this is similar to 'theory of mind' but goes beyond that since it assumes some affective reaction (e.g. a symapthetic reaction to someone else's distress). Thus, it might be that females are less supportive of animal use because they are more likely to attribute mental states to animals, and more likely to have a sympathetic reaction to this if they believe that animal use will cause some kind of pain or distress to animals.

Others have examined sex role orientation (SRO) in relation to attitudes toward animal use (Herzog, Betchart, and Pittman 1991; Peek, Dunham, and Dietz 1997), leading to mixed findings. Some suggest differences in attitudes as associated with feminine versus masculine SRO (Herzog, Betchart, and Pittman 1991), whereas Peek, Dunham, and Dietz (1997) argued that sex differences differ not as a result of SRO, but that the structural location of females in society better explains gender differences (see Adams 1994). That is, females identify with animals and animal rights issues because they perceive themselves and animals to have similar locations in society (i.e. beneath males) due to patriarchal oppression, and thus females tend to express more egalitarian and non-hierarchical ideologies. Herzog, Betchart, and Pittman (1991) proposed theoretical reasons for gender differences that included: (i) the sociocultural perspective, that women are socialised to care and nurture, whilst boys are encouraged to be less emotional and more utilitarian; (ii) biological reasoning that males see animals as a means to their survival, for example in terms of providing food, and also as a possible threat; (iii) the cognitive developmental view that males and females have different moral orientations that influence their perspective of animals (see Kellert and Berry 1987); and (iv) that femininity leads to a more nurturance-expressive dimension of personality that is more highly related to concern for animal welfare, whilst masculinity relates to less sensitivity to the ethical treatment of other creatures. Further, Furnham and Pinder (1990) related gender differences to the work of Ekehammar (1985) who described gender differences on various ideological dimensions- females presenting more liberal views whilst males were more conservative. Differences between males and females in attitudes towards animal use may relate to these differences in ideological views, with females more likely to challenge societal norms whilst males may be more accepting of conventional 
practices such as animal use (Furnham and Pinder 1990). Alternatively, females may have different moral orientations to males, basing judgements on caring whereas males tend to focus on justice (Gilligan 1982). In all, an interplay between socialisation forces and structural forces are likely to underlie gender differences (Peek, Dunham, and Dietz 1997), and sex differences are so large on almost all dimensions of attitudes toward animals that males and females probably have different emotional and cognitive orientations towards animals (Kellert and Berry 1987).

\section{Age}

Applegate (1973) found that older people were more supportive of deer hunting, whilst Kellert and Berry (1981) suggested that generally younger people are more concerned about animal use than older people. More recent research (Driscoll 1992; Furnham and Pinder 1990) found that young people rated examples of animal research as less acceptable than did older groups of participants. Kellert and Berry (1987) described how older males presented a more utilitarian view towards animals, suggesting that the practical value of animals increases in relevance with age as work and familial responsibilities become more important. From an evolutionary perspective it may be that as people get older, their priorities change as children and family become top priority, whilst animals are perceived as comparatively less important and seen in more functional terms. Further, Baron-Cohen (2003) suggests that mental attribution becomes more complex with age, so it might be that there are age differences in BAM.

\section{Eating meat}

Demand for particular types of food is influenced primarily by social psychological factors such as beliefs, attitudes norms and values (Kalof, Dietz, Stern, and Guagnano 1999), and vegetarianism is related to value orientations such as an increase in altruistic values and a decrease in traditional values (Dietz, Frisch, Kalof, Stern, and Guagnano 1995). Moreover, vegetarianism may relate to a wider ideological perspective in terms of the 'world view' held by people (Buss, Craik and Dake 1986; Furnham and Pinder 1990). Buss, Craik, and Dake (1986) identified two types of world view- one that values a high growth, high technology society, materialistic goals, and rational quantified decision-making processes, the other appreciating less material and technological growth, redistribution of wealth, goals of self-actualisation, and decision making determined by non-materialistic values (people holding the former view would be more likely to eat meat compared to those holding the latter view). Thus there may be ideological differences between vegetarians and non-vegetarians in terms of personal values and guiding principles that are extended to their views on other social issues such as feminism and 
wealth. Also, it may be that BAM is one reason why people abstain from eating animals and using animals in other ways. However, eating meat is a variable that in itself may be seen to represent an attitude towards animals- that is for some reason animals should not be eaten- and as such it is variable that differs in its nature compared to other participant characteristics such as age and gender.

\section{Political stance and living area}

The media often portrays blood sports and animal management issues as a political argument or a town-versus-country debate (e.g. Barnett 2000; Hunt 2000; Day-Lewis 2001). For example fox hunting has been presented as a sport supported by people with a more right-wing political stance, and people from more urban backgrounds have been portrayed as against hunting due to ignorance of country life. Research has shown that people who are left-wing oriented are less supportive of animal experimentation research, which may reflect differences in peoples 'world view' (see Buss, Craik, and Dake 1986), in that attitudes towards animals are closely related to attitudes towards other political and social matters (Furnham and Pinder 1990). Further, people from more urban backgrounds present more positive attitudes toward animals (Kalof et al. 1999), whilst people from less industrialised, less urbanised countries may be more supportive of animal use (Pifer, Shimizu, and Pifer 1994).

\section{Attitudes toward different types of animal use}

Previous research has suggested that attitudes towards animal use are one uni-dimensional factor (e.g. Armstrong and Hutchins 1996; Matthews and Herzog 1997). However, people can hold different attitudes towards different ways in which animals are used, for example people may be less supportive of uses that lead to death of animals (such as experimentation) compared to non-lethal uses (such as for entertainment) (Wells and Hepper 1997). Consequently, in the present study attitudes toward six different types of animal use were examined. Four of these were identified as themes that consistently emerge as important from animal rights literature (Armstrong and Hutchins 1996): 'using animals for experimentation'; 'using animals in the classroom'; 'using animals for personal decoration'; and 'animal management' issues. Two other categories were included based on our own ideas and other previous research (Matthews and Herzog 1997): 'using animals for entertainment', and 'using animals for financial gain'. 


\section{The present study}

This study developed and used a questionnaire to measure attitudes toward animal use and BAM. It was predicted that there would be significant differences between different types of animal use (Hypothesis 1), that females would be less supportive of animal use compared to males (Hypothesis 2), as would participants with more experience of animals compared to those with less experience (Hypothesis 3), and participants with higher levels of BAM compared to those with lower levels (Hypothesis 4). Also, that older participants would be more supportive of animal use (Hypothesis 5), as would non-vegetarians compared to vegetarians (Hypothesis 6), participants who rated themselves as more right-wing compared to those who were more leftwing (Hypothesis 7), and those who grew up in more rural areas compared to those from more urban areas (Hypothesis 8). Finally, we predicted that females would present higher levels of BAM compared to males (Hypothesis 9).

\section{Method}

\section{Participants}

A convenience sample of 96 participants took part (41 males, 55 females), with an average age of 39.32 years $(\underline{\mathrm{SD}}=13.90)$. Sixty-three $(65.6 \%)$ were pet-owners at present, $85(88.5 \%)$ were meat-eaters $(88.5 \%), 13(13.5 \%)$ responded that their political stance was 'left-wing' or' somewhat left-wing', 27 (28.1\%) 'somewhat' or 'very right-wing', whilst 56 (58.3\%) were 'neutral' (none responded that they were 'very right-wing' or 'very left-wing'). In terms of where they grew up $35(36.4 \%)$ responded 'very rural' or 'somewhat rural', 34 (35.4\%) 'somewhat urban' or 'very urban', and $27(28.2 \%)$ responded to the 'neutral' option.

Design

A questionnaire design was used for this study (see Appendix A for all statements, their sources, and categories), to measure attitudes towards 6 different types of animal use and BAM. Statements were responded to using a 7-point Likert scale (from strongly agree to strongly disagree).

\section{Procedure}

A convenience sample of people in public places in the Portsmouth (United Kingdom) area (i.e. the local shopping precinct and ferry terminals) were asked to complete the questionnaire (approximately half of those approached chose not to participate). The experimenter aimed for a fairly equal distribution of gender, and a wide age-range (with a minimum age of 18 years, in 
order to avoid problems with informed consent). Completing the questionnaire took between 1020 minutes.

\section{Coding}

Statements were coded so that the higher the score, the more support for animal use and higher levels of BAM.

Examining the reliability of the questionnaire

To test for reliability Cronbach's alpha was calculated to measure the internal consistency of each category. Internal consistency was high for all of the animal use categories: experimentation $($ Cronbach's alpha $=.88)$, classroom use $($ Cronbach's alpha $=.74)$, personal decoration $($ Cronbach's alpha $=.85)$, entertainment $($ Cronbach's alpha $=.70)$, animal management $($ Cronbach's alpha $=.77)$, and financial gain $($ Cronbach's alpha $=.67)$, whilst reliability for BAM was lower (Cronbach's alpha $=.62)$.

\section{Correlations between animal use categories}

To examine whether there was a relationship between attitudes towards the different types of animal use, Pearson's correlations were conducted (see Table 1). High correlations between all categories indicated strong relationships between attitudes towards different ways in which animals are used ${ }^{\mathrm{i}}$.

Table 1 about here

\section{Results}

Attitudinal responses to the eight categories of statements

Mean scores for each category are shown in Table 2 (higher scores represent more support for animal use and higher levels of BAM, and subscripts indicate where differences lie). A repeated measures ANOVA revealed significant differences between some of these six different types of animal use categories $(\underline{F}(5,475)=88.40, p<.001)$

Table 2 about here

Participants were significantly more supportive of using animals for experimentation and in the classroom than for other types of animal use. Scores for animal management issues were significantly lower than those for experimentation and classroom issues but significantly higher than scores for personal decoration, entertainment and financial gain. Least support was shown for the latter three categories (which were significantly lower than all other scores but not significantly different from each other) (therefore hypothesis 1 was accepted). 
Participant variables, attitudes towards animal use and BAM

Correlations and standard regression analyses were conducted to examine the predictive value of participant variables and BAM on scores for different types of animal use (see Table 3).

Table 3 about here

\section{Correlations between participant variables and attitudes towards animal use}

First, lower levels of BAM, being male, eating meat, and living in more urban areas were related to higher levels of support for animal experimentation (providing support for Hypotheses 2, 4, 6 and 8). Second, lower levels of BAM, being male, and eating meat, were associated with more support for using animals for personal decoration, for entertainment, for financial gain, and animal management issues (providing support for Hypotheses 2, 4 and 6). Third, lower levels of BAM and eating meat were related to higher levels of support for using animals in the classroom (providing support for Hypotheses 4 and 6).

\section{Regression analyses examining participant variables as predictors of attitudes towards animal use}

As recommended by Field (2000), in order to establish which variables were important predictors (BAM, gender, eating meat, experience of animals, political stance and living area) of attitudes towards the six different types of animal use, standard regression analyses were conducted. Next, regression analyses were repeated, but this time excluding those predictors that were revealed as unimportant in the original analyses, with the forward stepwise technique used to clarify which predictors were most important (only these latter findings are discussed).

For attitudes towards using animals for experimentation, BAM, gender, eating meat, and living area accounted for $46.5 \%$ of the variance. Females were less supportive $(\underline{\mathrm{M}}=3.18, \underline{\mathrm{SD}}=$ 1.50) compared to males $(\underline{\mathrm{M}}=4.27, \underline{\mathrm{SD}}=1.58)$, as were those who did not eat meat $(\underline{\mathrm{M}}=1.82$, $\underline{\mathrm{SD}}=1.01)$ compared to those who $\operatorname{did}(\underline{\mathrm{M}}=3.88, \underline{\mathrm{SD}}=1.53)$, and those from more urban backgrounds compared to those from more rural backgrounds (supporting Hypotheses 2, 4, and 6, but contradicting Hypothesis 8).

BAM and eating meat accounted for $30 \%$ of the variance in attitudes towards using animals in the classroom. Those who did not eat meat were less supportive of using animals in the classroom $(\underline{\mathrm{M}}=2.76, \underline{\mathrm{SD}}=1.16)$ compared to those who did $(\underline{\mathrm{M}}=3.75, \underline{\mathrm{SD}}=1.17)$ (supporting Hypotheses 4 and 6).

BAM and eating meat were again significant predictors of attitudes towards using animals for personal decoration, accounting for $37.7 \%$ of the variance. Participants who did not eat meat 
$(\underline{\mathrm{M}}=1.18, \underline{\mathrm{SD}}=1.21)$ compared those who did $(\underline{\mathrm{M}}=2.21, \underline{\mathrm{SD}}=1.23)$ were less supportive of using animals for personal decoration (supporting Hypotheses 4 and 6).

For attitudes towards using animals for entertainment, BAM and gender accounted for $35 \%$ of the variance. Females were less supportive of using animals for entertainment $(\underline{\mathrm{M}}=1.90$, $\underline{\mathrm{SD}}=.93)$, compared to males $(\underline{\mathrm{M}}=2.58, \underline{\mathrm{SD}}=1.07)$ (supporting Hypotheses 2 and 4).

BAM, age, gender and eating meat were significant predictors of attitudes towards animal management, accounting for $47 \%$ of the variance. Age increased as support decreased, females showed less support for animal management $(\underline{\mathrm{M}}=2.71, \underline{\mathrm{SD}}=1.61)$ than males $(\underline{\mathrm{M}}=3.56, \underline{\mathrm{SD}}=$ 1.17), as did those who did not eat meat $(\underline{\mathrm{M}}=2.11, \underline{\mathrm{SD}}=.90)$ compared to those who did $(\underline{\mathrm{M}}=$ 3.20, $\underline{\mathrm{SD}}=1.13)($ supporting Hypotheses 2, 4, 5 and 6).

Finally, BAM, gender and eating meat accounted for $37.6 \%$ of the variance in scores for using animals for financial gain. Again, females were less likely to support financial gain as a justification for using animals $(\underline{\mathrm{M}}=1.90, \underline{\mathrm{SD}}=.78)$ compared to males $(\underline{\mathrm{M}}=2.38, \underline{\mathrm{SD}}=.94)$, as were those who did not eat meat $(\underline{\mathrm{M}}=1.38, \underline{\mathrm{SD}}=.47)$ compared to those who did $(\underline{\mathrm{M}}=2.20, \underline{\mathrm{SD}}$ $=.88$ ) (providing further support for Hypotheses 2, 4 and 6).

\section{Participant variables and BAM}

Correlations examining relationships between participant variables and BAM found only one significant positive correlation that was between BAM and age. Furthermore, age emerged as the only significant predictor of BAM when regression analysis was conducted, accounting alone for 9\% of the variance in scores (see Table 4) (therefore Hypothesis 9 was not supported).

Table 4 about here

\section{Discussion}

Whilst previous research in this area has tended to use unrepresentative samples, this study used a non-student sample to examine attitudes towards animal use and Belief in Animal Mind (BAM). It was found that participants had significantly different attitudes towards different types of animal use, and belief in animal mind (BAM), gender and eating meat were related to attitudes towards animal use, with BAM clearly the most powerful and consistent predictor of attitudes towards all types of animal use. Higher levels of BAM were related to less support for animal use (as was being female and not eating meat). Age had a small but significant effect on BAM, with older participants presenting higher levels of BAM. Little evidence was found for relationships between attitudes and beliefs and the other participant variables examined. 
Previous studies have found variables such as gender and age to account for only a small (although significant) amount of variance in attitudes toward animal use (Driscoll 1992). This study however found BAM to be a much stronger predictor of attitudes. This may relate to an increase in BAM in the past decade, for example due to publicized research and television programmes people may be generally more knowledgeable about animal cognition (H.A. Herzog, personal communication, November, 2002), and thus BAM may have increased in its impact on attitudes toward animal use. If this is the case then BAM may go a long way in helping us to understand people's attitudes towards the treatment of animals compared to other variables such as gender and age. It seems likely that one reason for the relationship between BAM and attitudes towards animal use is that lower levels of BAM mean that people consider animals more as mechanical objects than thinking, feeling creatures, and thus support animal use since the animals involved cannot be mentally harmed by such use. Higher levels of BAM introduce a moral dilemma to people, since they have to decide whether pain and/or distress inflicted on the animal (that they believe the animal is capable of experiencing) can be justified. However, this does not explain why BAM does not seem to be related to eating meat, and it might be that BAM is only a correlate of attitudes towards animal use and there is a higher-order factor that we have yet to identify. Future research needs to recognise the large impact of this factor compared to other participant variables, whilst examining this relationship in more depth. Also, this study did not find a causal relationship between BAM and attitudes, and thus experimental designs that involve the manipulation of BAM will enhance our understanding of this relationship further (see Opotow 1993, for a method that might be used).

\section{Different attitudes towards different types of animal use}

Since the effects of BAM, gender and eating meat rarely differed according to type of animal use in question, and high correlations between categories of animal use were found, suggests that there may not be a clear distinction between these categories. However, analysing the data separately for each category made sense because we wanted to see if people had different views on different ways in which animals are used, and significant differences found between categories showed that this is the case.

\section{Gender differences}

Consistent with previous research, females were found to be significantly less supportive of animal use. However, the mean scores for each category across gender showed that men's ratings were around or below the middle of the Likert scale, indicating that male support for 
animal use was also limited. Thus gender may a less important factor in relation to attitudes towards animal use than first imagined. Indeed, whilst gender and SRO are consistent factors in relation to attitudes towards animal use, they can account for only a small amount of the variance (e.g. Herzog, Betchart, and Pittman 1991; Driscoll 1992).

\section{Eating meat}

Eating meat had a similar relationship to that of gender on attitudes- that is, whilst meat eaters were more supportive of animal uses, again mean scores for meat-eaters were all below the middle of the scale. This suggests that the meat eaters were not generally supportive of animal use. No significant differences were found between those participants who did and did not eat meat for levels of BAM, suggesting that higher levels of BAM do not lead to not eating meat (nor vice versa).

Age

Little support was found for relationships between attitudes and age, although younger participants were significantly less supportive of animal management issues. All statements in this category described animal use that involved wild animals (e.g. birds and mice) in their natural environment, and so it may be that younger people have different views towards wild animals in their natural environment compared to, for example, domesticated or farm animals. Indeed, Kellert and Berry (1981) discussed how younger people preferred animal life and the outdoor environment, so perhaps there is only a relationship between age and attitudes towards animal use when wild animals are concerned. This may be because younger people are more likely to take part in outdoor activities, or because they are a cohort that have been educated to be more aware of environmental issues such as conservation due to rising concerns in the past decade over pollution, the ozone layer, and so on. The younger cohort may also have had more exposure to animal welfare issues and procedures, and egalitarian views towards politics and animal rights. Further work is needed to investigate the effects of age on attitudes towards animal use.

\section{Experience of animals}

Although previous findings have reported a strong relationship between pet ownership and attitudes towards animal use (Paul and Serpell 1993), this was not the case in the present study. However, since others suggest that this factor accounts for only a small amount of variability in attitudes (Driscoll 1992), it may be that whilst pet ownership might influence 
attitudes towards animals (or vice versa), the relationship may not be a strong one. Alternatively, Paul and Serpell (1993) recommended that experience of animals be measured in terms of the quality of experience rather than experience per se, and the 'contact hypothesis' suggests that it is intimate relationships (e.g. friendships) that are influential in changing inter-group attitudes ( Hamberger and Hewstone 1997). This study used pet ownership as a measure of experience of animals, rather than pets perceived to be important, thus studies in the future might need to use more refined ways to measure experience of animals. One final point is that the relatively small sample size used in this study may have led to Type 2 errors, and thus a relationship that does exist may not be evident. Again. future research is needed to clarify this issue.

\section{Political stance and living area}

No evidence was found for a relationship between political stance, living area, and attitudes towards using animals. Thus it seems that attitudes towards animal use are not political nor are they influenced by living area, despite journalists indicating this to be the case. Alternatively, again a Type 2 error due to the relatively small sample size may have obscured a relationship between these variables and so further investigation in this area is necessary.

\section{Participant characteristics and BAM}

Age was the only predictor of BAM (with BAM increasing with age), although there was no relationship between age and attitudes towards animal use. Thus it seems that low levels of support shown by younger people may be due to reasons other than BAM (such as an increase in education relating to environmental issues or more egalitarian perspectives on life), regardless of BAM, whilst older people may be less supportive of animal use due to higher levels of BAM. Baron-Cohen (2003) suggested that mental attribution becomes more complex with age, yet differences between male and female brains (in empathizing and systemizing) can be observed and studied from one year of age (Baron-Cohen, Tager-Flusberg, and Cohen 1994). Future research might explore (i) gender differences in children relating to BAM and attitudes towards animal use from Baron-Cohen's perpective, and (ii) how age, attitudes towards animal use, and BAM might be inter-related.

\section{Different attitudes and BAM for different species of animals}

This study measured BAM and attitudes towards animal use of animals in general, with only several of the statements referring to particular species of animals. This may have confounded results if participants have different views on BAM and animal use depending upon 
the species of animal involved. Thus future research may specify particular types of animals when examining such views and beliefs, since the term 'animal' may be too broad when measuring such attitudes. Another problem with the questionnaire used in this study is that the reliability of the BAM subscale was relatively low (although acceptable), thus indicating that future research might need a better measure for this variable (see Herzog \& Galvin 1997, for an alternative measuring tool).

\section{Socio-psychological factors and attitudes towards animal use}

Future research should also consider socio-psychological factors (such as moral orientation and ethical ideology) that underlie attitudes toward the treatment of animals. For example, Galvin and Herzog (1992) found that animal rights activists held 'absolutist' moral orientation, that is they believed that there are universal moral principles that should be adhered to, and that adherence would lead to positive consequences. Furthermore, the idea that people hold a 'world view' (Buss, Craik and Dake 1986) suggests that attitudes towards animals and the environment are closely inter-related with attitudes towards other social and political issues (Furnham and Pinder 1990; Pifer, Shimizu, and Pifer 1994). In addition to such orientation, a persons position in society may be related to attitudes, for example females and Blacks may have had similar experiences of subordination may therefore empathise more with the treatment of animals (Kalof et al. 1999). Thus structural location and ethical idealism may relate to empathy that is extended to other living creatures (Galvin and Herzog 1992).

\section{Conclusions}

Findings from the present study show BAM to be a strong and consistent predictor of different types of animal use. If BAM has increased in recent times due to publicity relating to animal cognition then this would explain why this factor seems to have such a crucial impact on attitudes toward the treatment of animals. Moreover, our results showed that attitudes do differ depending on the different types of animal use in question, and we suggest that future research should investigate attitudes towards animal use accordingly. The present study used a non-student sample so it is hoped that findings are more representative than those of past research that used students only as participants. Although there are disadvantages with using convenience samples (e.g. a high refusal rate can skew findings), we are optimistic that findings from this study may enhance understanding of attitudes toward how animals are used in our society. 


\section{References}

Adams, C.J. 1994. Bringing peace home: A feminist philosophical perspective on the abuse of women, children and pet animals. Hypatia 9: 63-84.

Allport, G.W. 1954. The nature of prejudice. Cambridge, MA: Beacon Press.

Applegate, J.E. 1973. Some factors associated with attitude toward deer hunting in New Jersey residents. Transactions American Wildlife and Natural Resource Conference 38: 267-273.

Armstrong, J.B., and Hutchins, M.E. 1996. Development of an attitude scale to measure attitudes toward humans' use of nonhuman animals. Perceptual and Motor Skills 82: 1003-1010.

Barnett, A. March 19th, 2000. Bloody Truth Behind. The Observer.

Baron-Cohen, S. (2003). The essential difference: Men, women and the extreme male brain. London: Allen Lane.

Baron-Cohen, S., Tager-Flusberg, H., and Cohen, D. (1994). Understanding other minds: Perspectives from autism. London: Oxford University Press.

Baron-Cohen, S., Wheelwright, S., Lawson, J., Griffin, R., \& Hill, J. (2002). The exact mind: Empathizing and systemizing in autism spectrum conditions. In The Blackwell Handbook of childhood cognitive development, ed. U.Goswami. Malden, USA: Blackwell publishers, 491-508. Buss, D., Craik, K., and Dake, K. 1986. Contemporary world views on technology and resources: Their political attitudinal content. Journal of Applied Social Psychology 15. Day-Lewis, T. February 3rd, 2001. Playing by the rules of the game. The Daily Telegraph. Dietz, T., Frisch, A.S., Kalof,L., Stern, P.C., and Guagnano, G.A. 1995. Values and vegetarianism: An exploratory analysis. Rural Sociology 60: 533-542.

Driscoll, J.W. 1992. Attitudes Towards Animal Use. Anthrozoos 5: 32-39.

Eddy, T.J., Gallup, G.G., and Povinelli, D.J. 1993. Attribution of cognitive states to animals: Anthropomorphism in comparative perspective. Journal of Social Issues 49: 87-101.

Ekehammar, B. 1985. Sex differences in socio-political attitudes revisited. Educational Studies 11: 3-9.

Field, A. 2000. Discovering Statistics using SPSS for Windows. London: Sage.

Furnham, A., and Pinder, A. 1990. Young people's attitudes to experimentation on animals. The Psychologist October: 444-448.

Galvin, S.L. and Herzog, H.A. 1992. Ethical ideology, animal rights activism, and attitudes toward the treatment of animals. Ethics and Behavior 2: 141-149.

Gilligan, C. 1982. In a different voice. Cambridge, MA: Harvard University Press. 
Hamberger, J. and Hewstone, M. 1997. Inter-ethnic contact as a predictor of blatant and subtle prejudice: Tests of a model in four West European nations. British Journal of Social Psychology 36: 173-190.

Heider, F. 1944. Social perception and phenomenal causality. Psychological Review 51: 358374.

Herzog, H.A., Betchart, N.S., and Pittman, R.B. 1991. Gender, sex role orientation, and attitudes towards animals. Anthrozoos 4: 184-191.

Herzog, H.A., and Dorr, L.B. 2000. Electronically Available Surveys of Attitudes Toward Animals. Society and Animals 8: 183-190.

Herzog, H.A., and Galvin, S. 1997. Common Sense and the Mental Lives of Animals: An Empirical Approach. In Anthropomorphism, Anecdotes and Animals, ed. R.W. Mitchell. Albany: State University of New York Press, 237-253.

Hills, A.M. 1995. Empathy and Belief in the Mental Experience of Animals. Reviews and Research Reports. Anthrozoos 8: 132- 142.

Hunt, M. 2000, December 18. New Labour tries to run with the fox and hunt with the hounds. The Times: Internet Edition [Online]. Available: http://www.the-times.co.uk [Accessed: 2001, October 9].

Kafer, R., Lago, D., Wamboldt, P., and Harrington, F. 1992. The pet relationship scalereplication of psychometric properties in random samples and association with attitudes toward wild animals. Anthrozoos 5: 93-105.

Kalof, L., Dietz, T., Stern, P.C., and Guagnano, G.A. 1999. Social psychological and structural influences on vegetarian beliefs. Rural Sociology 64: 500-511.

Kellert, S.R., and Berry, J.K. 1981. Knowledge, affection and basic attitudes toward animals in American society. Springfield, Va.: National Technical Information Service, PB-81-173106. Kellert, S.R., and Berry, J.K. 1987. Attitudes, knowledge, and behaviors toward wildlife as affected by gender. Wildlife Society Bulletin 15: 363-371.

Kemdal, A.B. and Montgomery, H. 2001. Explaining own and others behavior in a controversial issue: Animal experimentation. The Journal of Social Psychology 141: 693-713.

Lieberman, A. and Chaiken, S. 1996. The direct effect of personal relevance on attitudes. Personality and Social Psychology Bulletin 22: 269-279.

Matthews, S., and Herzog, H.A. 1997. Personality and attitudes toward the treatment of animals. Society and Animals 5: 169-175.

Opotow, S. 1993. Animals and the scope of justice. Journal of Social Issues 49: 71-85. 
Paul, E.S., and Serpell, J.A. 1993. Childhood pet keeping and humane attitudes in young adulthood. Animal Welfare 2: 321-337.

Peek, C.W., Dunham, C.C., and Dietz, B.E. 1997. Gender, relational role orientation, and affinity for animal rights. Sex roles 37: 905-920.

Petty, R.E. and Cacioppo, J.T. 1990. Involvement and persuasion: Tradition versus integration. Psychological Bulletin 107: 367-374.

Pifer, L., Shimizu, K., and Pifer, R. 1994. Public attitudes toward animal research: Some international comparisons. Society and Animals 2: 95-113.

Plous, S. 1996. Attitudes toward the use of animals in Psychological research and education. Psychological Science 7: 352-358.

Rajecki, D.W., Rasmussen, J.L., and Craft, H.D. 1993. Labels and the Treatment of Animals: Archival and Experimental Cases. Society and Animals 1: 45-60.

Smith, E.R. and Mackie, D.M. 1995. Social Psychology. New York: Worth Publishers, Inc.. Wells, D.L., and Hepper, P.G. 1997. Pet Ownership and Adults' Views on the Use of Animals. Society and Animals 5: 45-63. 


\section{APPENDIX A}

\section{USING ANIMALS FOR EXPERIMENTATION}

1. New medical procedures should be tried on animals before they are tried on humans (Armstrong and Hutchins, 1996)

2. Much of scientific research done with animals is unnecessary and cruel (Matthews and Herzog, 1997)

3. Experimentation with animals is cruel, even if it saves human lives (Armstrong and Hutchins, 1996)

4. Continued research with animals will be necessary if we are to ever conquer diseases such as cancer, heart disease and AIDS (Matthews and Herzog, 1997)

5. It is acceptable to cause injury, distress or death to animals in research even if humans do not benefit from this (Armstrong and Hutchins, 1996)

\section{USING ANIMALS IN THE CLASSROOM}

1. I support university research that is done with animals if it does not cause distress, pain or death to the animal (Armstrong and Hutchins, 1996)

2. Students should be given alternatives to using real animals for dissection (Armstrong and Hutchins, 1996)

3. It is cruel to use and dispose of live microscopic animals for classroom purposes (Armstrong and Hutchins, 1996)

4. It is morally wrong to use animals in classrooms if the animal is harmed, distressed or injured (Armstrong and Hutchins, 1996)

5. It is alright to use dead animals in class laboratories if the animals were raised and killed humanely (Armstrong and Hutchins, 1996)

\section{USING ANIMALS FOR PERSONAL DECORATION}

1. In a Western society where man-made alternatives are available, it is wrong to kill animals for their fur (Armstrong and Hutchins, 1996)

2. Stores should sell more items such as jewellery and purses made with animal by-products (Armstrong and Hutchins, 1996)

3. Consumers should boycott companies that routinely use animals for testing their products (Armstrong and Hutchins, 1996)

4. Animals should be used to test personal products, such as soap, before they are marketed for people (Armstrong and Hutchins, 1996)

5. Breeding animals for their skins is a legitimate use of animals (Matthews and Herzog, 1997)

\section{USING ANIMALS FOR ENTERTAINMENT}

1. The use of animals for human entertainment such as rodeos, bull-fighting and circuses is cruel (Matthews and Herzog, 1997)

2. Zoos provide an acceptable environment for wild animals (Matthews and Herzog, 1997)

3. It is morally wrong to hunt wild animals just for sport (Matthews and Herzog, 1997)

4. There should be extremely harsh penalties including jail sentences for people who participate in dog-fighting and badger-baiting (Matthews and Herzog, 1997) 


\section{ANIMAL MANAGEMENT}

1. Hunting is an acceptable means for controlling overpopulation in wild animals (Armstrong and Hutchins, 1996)

2. Any bird that is a nuisance should be destroyed (Armstrong and Hutchins, 1996)

3. Household invaders such as mice and rats should be destroyed when in the house (Armstrong and Hutchins, 1996)

4. Wildlife in urban areas should be protected, even if it becomes a nuisance (Armstrong and Hutchins, 1996)

5. Animal management should focus research on non-lethal ways to manage groups of animals (Armstrong and Hutchins, 1996)

6. Farmers should use scarecrows/ bird-scarers rather than kill birds that damage their crops (Armstrong and Hutchins, 1996)

\section{USING ANIMALS FOR FINANCIAL GAIN}

1. Animal shelters should destroy stray animals because it costs money to keep them (Armstrong and Hutchins, 1996)

2. In general, I think that human economic gain is more important than setting aside more land for wildlife (Matthews and Herzog, 1997)

3. The slaughter of whales and dolphins should be immediately stopped even if it means some people will be out of work (Matthews and Herzog, 1997)

4. The production of inexpensive meat justifies maintaining animals under crowded and often painful conditions (Matthews and Herzog, 1997)

5. Battery farming chickens and hens is okay if it makes the price of their eggs lower (researchers own)

6. Foxes have a right to be protected from farmers, even if they damage their crops (Armstrong and Hutchins, 1996)

\section{BELIEF IN ANIMAL MIND (BAM) (all from Hills, 1995)}

1. Most animals are unaware of what is happening to them

2. Most animals are capable of experiencing a range of feelings and emotions (e.g. pain, fear, contentment, maternal affection)

3. Most animals are able to think to some extent to solve problems and make decisions about what to do

4. Most animals are more like computer programs, i.e. mechanically responding to instinctive urges without awareness of what they are doing 
Table 1.

Correlations between specific forms of animal use

\begin{tabular}{|c|c|c|c|c|c|c|}
\hline & Experimentation & Classroom & $\begin{array}{l}\text { Personal } \\
\text { decoration }\end{array}$ & Entertainment & Management & $\begin{array}{c}\text { Financial } \\
\text { gain }\end{array}$ \\
\hline \multicolumn{7}{|l|}{ Experimentation } \\
\hline Classroom & $.70^{* *}$ & & & & & \\
\hline $\begin{array}{l}\text { Personal } \\
\text { decoration }\end{array}$ & $.63^{* *}$ & $.52 * *$ & & & & \\
\hline Entertainment & $.50 * *$ & $.56^{* *}$ & $.68^{* *}$ & & & \\
\hline Management & $.63^{* *}$ & $.58^{* *}$ & $.60^{* *}$ & $.63^{* *}$ & & \\
\hline $\begin{array}{l}\text { Financial } \\
\text { gain }\end{array}$ & $.66^{* *}$ & $.50^{* * *}$ & $.65^{* *}$ & $.61 * *$ & $.56^{* *}$ & \\
\hline
\end{tabular}

** Correlation is significant at the 0.01 level (2-tailed). 
Table 2.

Mean responses to each category representing specific forms of animal use

\begin{tabular}{lcc}
\hline Category & mean score & SD \\
\hline Animal experimentation & $3.65_{\mathrm{a}}$ & 1.61 \\
Classroom use & $3.64_{\mathrm{a}}$ & 1.21 \\
Personal decoration & $2.09_{\mathrm{c}}$ & 1.21 \\
Entertainment & $2.19_{\mathrm{c}}$ & 1.05 \\
Animal management & $3.07_{\mathrm{b}}$ & 1.16 \\
Financial gain & $2.10_{\mathrm{c}}$ & .90 \\
& & \\
Animal mind & 5.77 & .96 \\
\hline
\end{tabular}

Note: Only means with a different subscript differ significantly from each other 
Table 3.

Correlations and regression analyses examining the effects of belief in animal mind (BAM) and participant variables on attitudes towards animal use

\begin{tabular}{|c|c|c|c|c|c|c|c|}
\hline & & Experimentation & Classroom & Decoration & Entertainment & Management & $\begin{array}{c}\text { Financial } \\
\text { gain }\end{array}$ \\
\hline $\mathrm{BAM}_{\mathrm{a}}$ & $\mathrm{r}$ & $-.46^{* *}$ & $-.46^{* *}$ & $-.53^{* *}$ & $-.51^{* *}$ & $-.52^{* * *}$ & $-.52^{* *}$ \\
\hline \multirow[t]{2}{*}{ Regression } & $\mathrm{B}$ & -.41 & -.45 & -.50 & -.49 & -.54 & -.49 \\
\hline & $\mathrm{t}$ & $-5.31^{* *}$ & $-5.02^{* *}$ & $-6.07^{* *}$ & $-5.91^{* *}$ & $-6.84^{* *}$ & $-5.94^{* *}$ \\
\hline $\mathrm{Age}_{\mathrm{a}}$ & $\mathrm{r}$ & .03 & .10 & .09 & -.03 & .17 & .04 \\
\hline \multirow[t]{2}{*}{ Regression } & $\mathrm{B}$ & - & - & - & - & .22 & - \\
\hline & $\mathrm{t}$ & - & - & - & - & $2.75^{* *}$ & - \\
\hline Gender $_{b}$ & $\mathrm{r}$ & $.34^{* *}$ & .16 & $.22^{*}$ & $.36^{* *}$ & $.37^{* *}$ & $.26^{* *}$ \\
\hline \multirow[t]{2}{*}{ Regression } & $\mathrm{B}$ & -.20 & - & -.18 & -.30 & -.26 & -.20 \\
\hline & $\mathrm{t}$ & $-2.51^{* *}$ & - & $-2.14^{*}$ & $-3.60^{* *}$ & $-3.25^{* *}$ & $-2.42^{*}$ \\
\hline Pet $_{\mathrm{b}}$ & $\mathrm{r}$ & -.10 & .01 & -.09 & -.17 & -.07 & -.06 \\
\hline \multirow[t]{2}{*}{ Regression } & $\mathrm{B}$ & - & - & - & - & - & - \\
\hline & $\mathrm{t}$ & - & - & - & - & - & - \\
\hline Meat $_{\mathrm{b}}$ & $\mathrm{r}$ & $.39^{* *}$ & $.23^{*}$ & $.30^{* *}$ & $.22^{*}$ & $.30^{* *}$ & $.33^{* *}$ \\
\hline \multirow[t]{2}{*}{ Regression } & $\mathrm{B}$ & -.39 & -.23 & -.20 & - & -.20 & -.23 \\
\hline & $\mathrm{t}$ & $-4.86^{* *}$ & $-2.59^{*}$ & $2.43^{*}$ & - & $-2.56^{*}$ & $-2.71^{* *}$ \\
\hline Politics $_{a}$ & $\mathrm{r}$ & .12 & .13 & .08 & -.06 & -.02 & -.02 \\
\hline \multirow[t]{2}{*}{ Regression } & $\mathrm{B}$ & - & - & - & - & - & - \\
\hline & $\mathrm{t}$ & - & - & - & - & - & - \\
\hline Area $_{a}$ & $\mathrm{r}$ & $-.22^{*}$ & -.03 & -.15 & -.06 & -.05 & -.13 \\
\hline \multirow[t]{5}{*}{ Regression } & $\mathrm{B}$ & .23 & - & - & - & - & - \\
\hline & $\mathrm{t}$ & $2.92^{* *}$ & - & - & - & - & - \\
\hline & $\mathrm{r}^{2}$ & $.46^{*}$ & $.27^{*}$ & $.37^{* *}$ & $.35^{* *}$ & $.47^{* *}$ & $.38^{* *}$ \\
\hline & $\mathrm{F}$ & 19.80 & 16.94 & 17.77 & 25.05 & 20.21 & 18.58 \\
\hline & $\mathrm{df}$ & 4,91 & 2,93 & 3,92 & 2,93 & 4,91 & 3,92 \\
\hline
\end{tabular}

a Pearson correlation conducted

b Spearmans correlation conducted

* Significant at the 0.05 level (1-tailed).

** Significant at the 0.01 level (1-tailed). 
Table 4.

Correlations and regressions analysis examining the relationship between participant variables and belief in animal mind (BAM)

\begin{tabular}{|c|c|c|}
\hline & & BAM \\
\hline Age $_{a}$ & $\mathrm{r}$ & $.28^{*}$ \\
\hline \multirow[t]{2}{*}{ Regression } & $\mathrm{B}$ & .29 \\
\hline & $\mathrm{t}$ & $2.63^{* *}$ \\
\hline Gender $_{b}$ & $\mathrm{r}$ & .05 \\
\hline \multirow[t]{2}{*}{ Regression } & $\mathrm{B}$ & - \\
\hline & $\mathrm{t}$ & - \\
\hline $\mathrm{Pet}_{\mathrm{b}}$ & $\mathrm{r}$ & -.13 \\
\hline \multirow[t]{2}{*}{ Regression } & $\mathrm{B}$ & - \\
\hline & $\mathrm{t}$ & - \\
\hline Meat $_{\mathrm{b}}$ & $\mathrm{r}$ & .08 \\
\hline \multirow[t]{2}{*}{ Regression } & $\mathrm{B}$ & - \\
\hline & $\mathrm{t}$ & - \\
\hline Politics $_{\mathrm{a}}$ & $\mathrm{r}$ & -.03 \\
\hline \multirow[t]{2}{*}{ Regression } & $\mathrm{B}$ & - \\
\hline & $\mathrm{t}$ & - \\
\hline Area $_{\mathrm{a}}$ & $\mathrm{r}$ & -.05 \\
\hline \multirow[t]{5}{*}{ Regression } & $\mathrm{B}$ & - \\
\hline & $\mathrm{t}$ & - \\
\hline & $\mathrm{r}^{2}$ & .05 \\
\hline & $\mathrm{F}$ & 5.35 \\
\hline & $\mathrm{df}$ & 1,94 \\
\hline \multicolumn{3}{|c|}{ a Pearson correlation conducted } \\
\hline \multicolumn{3}{|c|}{ b Spearmans correlation conducted } \\
\hline \multicolumn{3}{|c|}{ * Significant at the 0.05 level (1-tailed). } \\
\hline ** Significant a & evel (1-tailed). & \\
\hline
\end{tabular}

\section{ENDNOTES}

${ }^{\mathrm{i}}$ On the basis of high correlations between categories, factor analysis was conducted to ensure that the questionnaire was not assessing one common construct. This analysis revealed five distinct factors, i.e. factors consisting of 3 or more items (items interpreted as members of a factor if they had a loading of $>.40$ on one factor only). Unfortunately, only two of the original six categories emerged (one factor consisted of three out of the original four items from the 'financial gain' category, and a second factor consisted of four out of the original five items from the 'personal decoration' category). The remaining three factors did not reflect any of the factors initially predicted. 
However, since the factors that emerged from the factor analysis were difficult to interpret theoretically, it was decided that analysis would continue to examine data for the original six categories. 